\title{
Equatorial mountain lakes show extended periods of thermal stratification with recent climate change
}

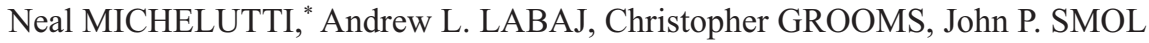 \\ Department of Biology, Paleoecological Environmental Assessment and Research Laboratory (PEARL), Queen's University, Kingston, \\ Ontario, Canada \\ *Corresponding author: nm37@queensu.ca
}

\begin{abstract}
Climate change in the Andes has already affected phenology, glaciology, and other ecosystem attributes, and now threatens to alter long-standing fundamental limnological properties. In the equatorial Andes, most lakes have traditionally been described as having waters that circulate continuously (polymictic), with only rare episodes of stratification. This characterization, albeit based on relatively few studies, is widely accepted, despite accelerated regional warming over the past 30 years. Here, we show that protracted periods of thermal stratification are presently the norm, not the exception, in equatorial mountain lakes. Annual circulation and stratification patterns recorded in four lakes from Ecuador's southern Sierra show extended periods of stratification, which are stable and do not break down with nocturnal cooling. These data contrast with earlier research from this region, which reported full water column mixing and only infrequent stratification, but are not surprising in light of recent trends toward rising temperatures and declining wind velocities. Paleolimnological studies show that changes to the thermal regimes of these lakes likely began several decades ago and have resulted in ecosystem-scale changes including regime shifts in phytoplankton and declines in aquatic production
\end{abstract}

Key words: Tropical Andes; Ecuador; lakes; climatic change; thermal stratification.

Received: January 2016. Accepted: March 2016.

\section{INTRODUCTION}

Lakes of the equatorial Andes sustain human life by supplying water for consumption, agriculture, fisheries and power generation (Herzog et al., 2011). Climate changes of the last several decades stand to negatively impact these critical water resources (Vuille, 2013). Air temperatures in the Andes have risen by $\sim 0.7^{\circ} \mathrm{C}$ between 1939 and 2006, with the most striking increases occurring since the 1970s (Vuille et al., 2008). Moreover, future warming is projected to be amongst the greatest here than for any region on the planet (Magrin et al., 2007; Diaz et al., 2014).

Arguably, the most important feature that influences lake ecosystem properties on a global scale is thermal stratification (Gerten et al., 2002). Lakes with water columns that circulate continuously function differently from those that are perennially stratified, with respect to fundamental properties including nutrient cycling, hypolimnetic oxygen concentrations, and plankton distribution (Hampton et al., 2014). Changes to these basic properties can have repercussions that reverberate through the food web (Gerten et al., 2002; Hampton et al., 2014). Climate-related changes to circulation and stratification patterns can set into motion trophic cascades, the effects of which can have serious societal implications for those who rely directly on lakes for their livelihoods (O'Reilly et al., 2003). This includes millions of Andean people for whom lakes serve as essential natural resources (Herzog et al., 2011).

Categorizing tropical Andean lakes according to their thermal stratification regimes is difficult because of the paucity of physical limnological studies from the region. Amongst the first to study physical properties in equatorial mountain lakes were Hutchinson and Löffler (1956), who noted that the lack of seasonality that permits nearly perennial stratification in low elevation tropical lakes likewise permits nearly perennial circulation in mountain lakes of similar latitude. Although this statement does not capture the full complexity of stratification patterns that can occur in tropical lakes (Lewis et al., 1973), in general, the few studies on equatorial high mountain lakes suggest that circulation is more or less continuous, and thermal stratification either does not occur or is short-lived and weak (Löffler, 1964; Steinitz-Kannan et al., 1983; Gunkel et al., 2002).

In the absence of direct measurements, paleolimnological studies can offer insight into historical patterns of mixing and circulation. For example, certain algal species require frequent mixing of the water column to survive, whereas others flourish under periods of sustained thermal stratification (Rühland et al 2015). In recent paleolimnological studies from the Andes of Ecuador and Peru, the examination of fossil algal assemblages showed sudden shifts in species composition during recent decades, which 
suggests a change in mixing regime from one of frequent circulation to extended periods of thermal stratification (Michelutti et al., 2015a, 2015b, 2016).

In this study, we documented patterns of mixing and circulation regimes from a suite of lakes in the equatorial Andes by recording temperature profiles over the time period of one year. Our study region in Cajas National Park, located in the southern Sierra of Ecuador (Fig. 1), is of high conservation value as it houses hundreds of lakes that are the source for $\sim 60 \%$ of the drinking water to Cuenca, the country's third largest city. The available physical limnological data from Cajas National Park indicates the lakes have historically experienced frequent periods of water column circulation (Steinitz-Kannan et al., 1983). However, recent paleolimnological studies from this lakerich region have documented abrupt changes in planktonic algal assemblages beginning within the last 50 years, which suggests the lakes have entered new physical states of extended periods of thermal stratification (Michelutti et al., 2015a). The timing of these changes coincides with regional records of rising air temperatures and declining wind speeds, which are two key variables that affect thermal stratification. Despite the paleolimnological evidence suggesting new limnological regimes for these lakes, the following questions still remained: Do the lakes in Cajas National Park stratify thermally? And if so, what is the duration and degree of stratification?

The intent of this study was to provide new data on stratification regimes for lakes in the equatorial Andes. The project was driven by the apparent disconnect between the few available studies of physical limnology that

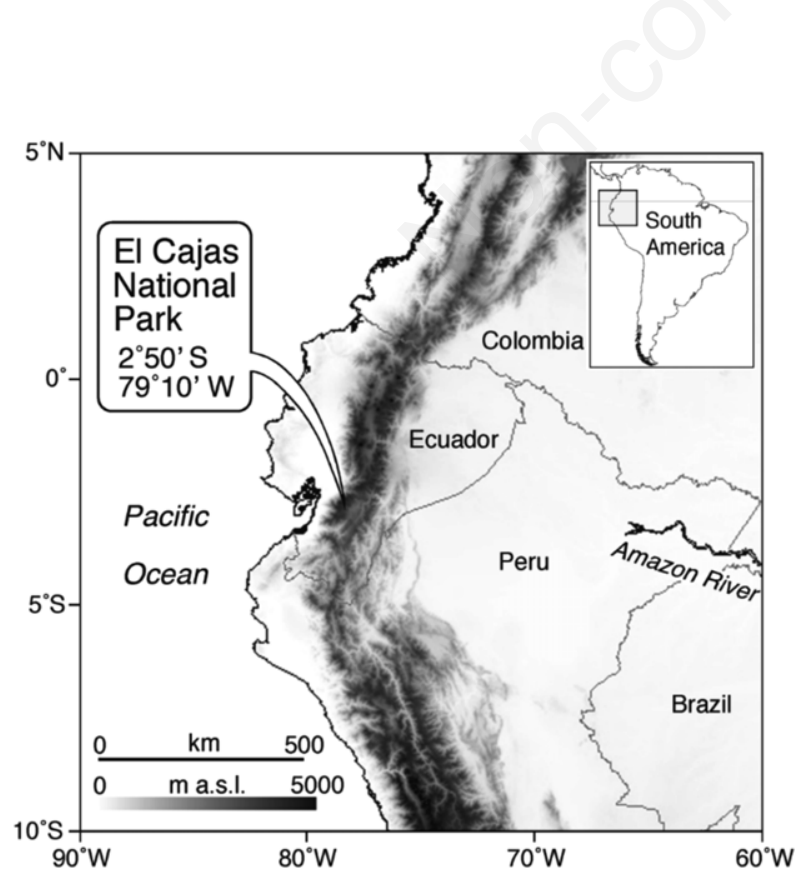

Fig. 1. Location of Cajas National Park in the southern Andes of Ecuador. indicate circulation is more or less continuous (SteinitzKannan et al., 1983) and the paleolimnological studies that suggest the lakes have entered new regimes of extended stratification (Michelutti et al., 2015a). These newly acquired water temperature data will determine the validity of our paleolimnological assertion that thermal stratification is now prevalent in Cajas Park lakes. On a broader scale, these data will provide insight into whether the climate changes of recent decades (Vuille et al., 2008) have initiated a potential regime shift in stratification patterns of lakes throughout the tropical Andes as inferred from paleolimnological studies (Michelutti et al. 2015a, 2015b, 2016).

\section{METHODS}

In August 2014, water temperature data loggers (HOBO Water Temperature Pro v2 Data Logger) were deployed in four lakes in Cajas National Park (S $2^{\circ} 83^{\prime}, \mathrm{W}$ $79^{\circ} 17^{\prime}$; Fig. 1). The four study sites (Supplementary Figs. 1-4) are located within $\sim 10 \mathrm{~km}$ of one another and were selected to reflect differences in elevation and lake morphometry in order to obtain a regional signal of circulation and stratification patterns. The study lakes span an elevation gradient from 3,140 to $4,160 \mathrm{~m}$ asl and have comparable limnological properties, each being circumneutral in $\mathrm{pH}$, dilute, and ultra-oligotrophic (Michelutti et al., 2015a; Supplementary Tab. 1). Ten data loggers for each lake were positioned nearest the deepest portion of each basin, and placed along depth profiles at equidistant spacing from the surface to the bottom, at intervals ranging from $\sim 1$ to $2 \mathrm{~m}$. Temperature was recorded every hour at each depth interval over a period of one year.

Mean annual temperature (1960 to 2008) recorded at the nearby Cañar meteorological station ( $\sim 30 \mathrm{~km}$ away) was $11.3^{\circ} \mathrm{C}$. Annual precipitation in the park ranges from $829 \mathrm{~mm}$ to $1343 \mathrm{~mm}$. The seasonality of precipitation in the Ecuadorian Andes is bimodal, with two main wet seasons from March to May and September until November (Vuille et al., 2013). Annual variations in daily solar radiation are minimal, and there is little evapotranspiration. Air temperature data for 2014 are from hourly readings from a temperature data logger (HOBO Water Temperature Pro v2 Data Logger) that was placed in a shaded region of the catchment of one of the study sites (Laguna Toreadora). Wind speeds are monthly means from NCEP/NCAR re-analyses (Kalnay et al., 1996), at 500 hPa levels, based on a $3^{\circ} \times 3^{\circ}$ grid average covering Ecuador $\left(0-5^{\circ} \mathrm{S}, 77.5-82.5^{\circ} \mathrm{W}\right)$.

\section{RESULTS AND DISCUSSION}

All study lakes showed extended periods of thermal stratification, with maximum temperature differences between surface and bottom waters in the range of $\sim 6-7^{\circ} \mathrm{C}$ 
(Fig. 2). Importantly, this stratification is stable and does not break down with nighttime cooling (Supplementary Fig 5). The lakes are thermally stratified by at least $2^{\circ} \mathrm{C}$ between $46 \%$ (Fondococha) to $76 \%$ (Patoquinas) of the year. Predictably, elevation and lake depth were important factors influencing the thermal regimes. The lowest elevation lake (Llaviucu at $3140 \mathrm{~m}$ asl) recorded the warmest surface water temperatures with fewest isothermal condi-
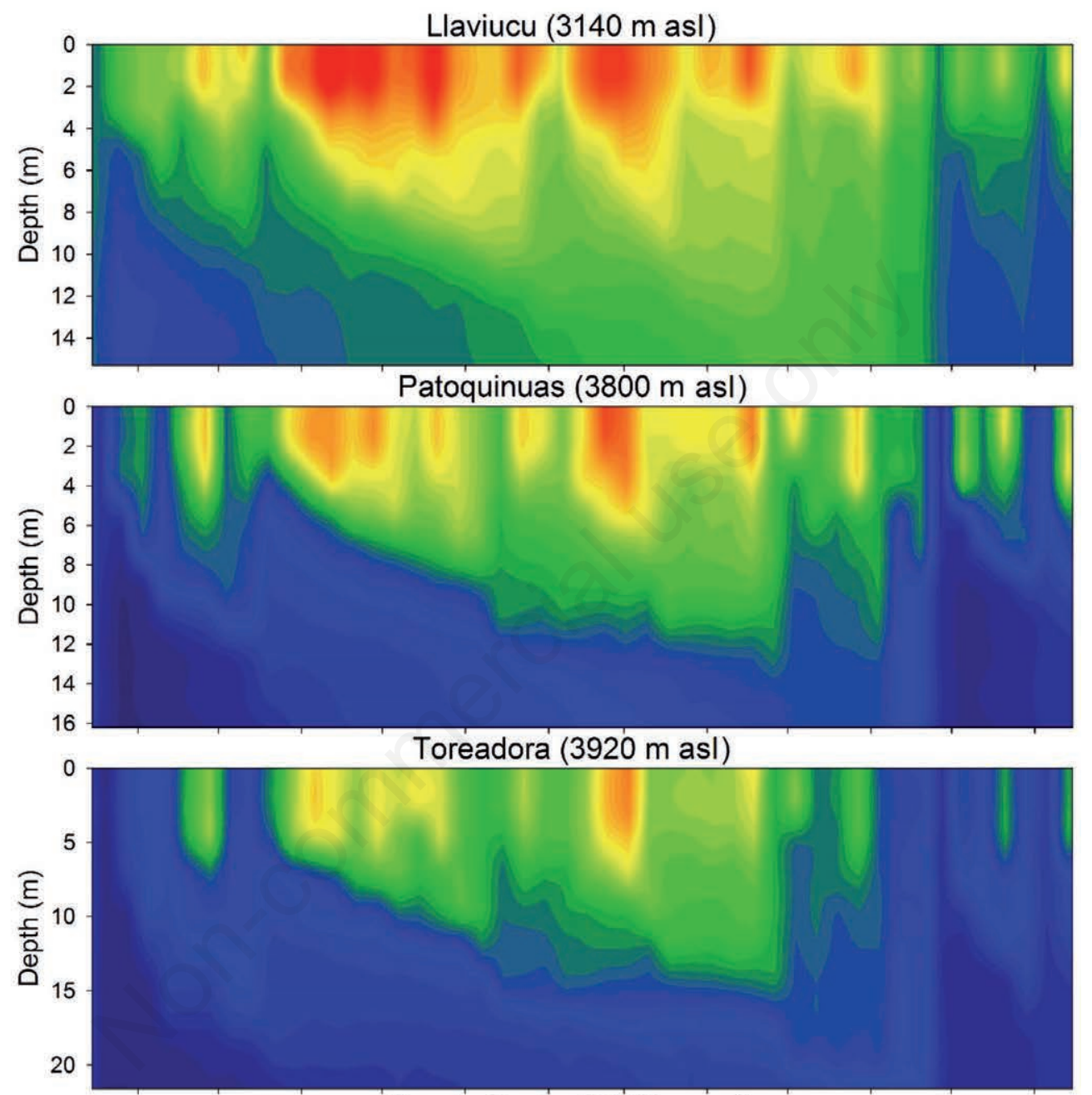

Fondo Cocha (4160 m asl)

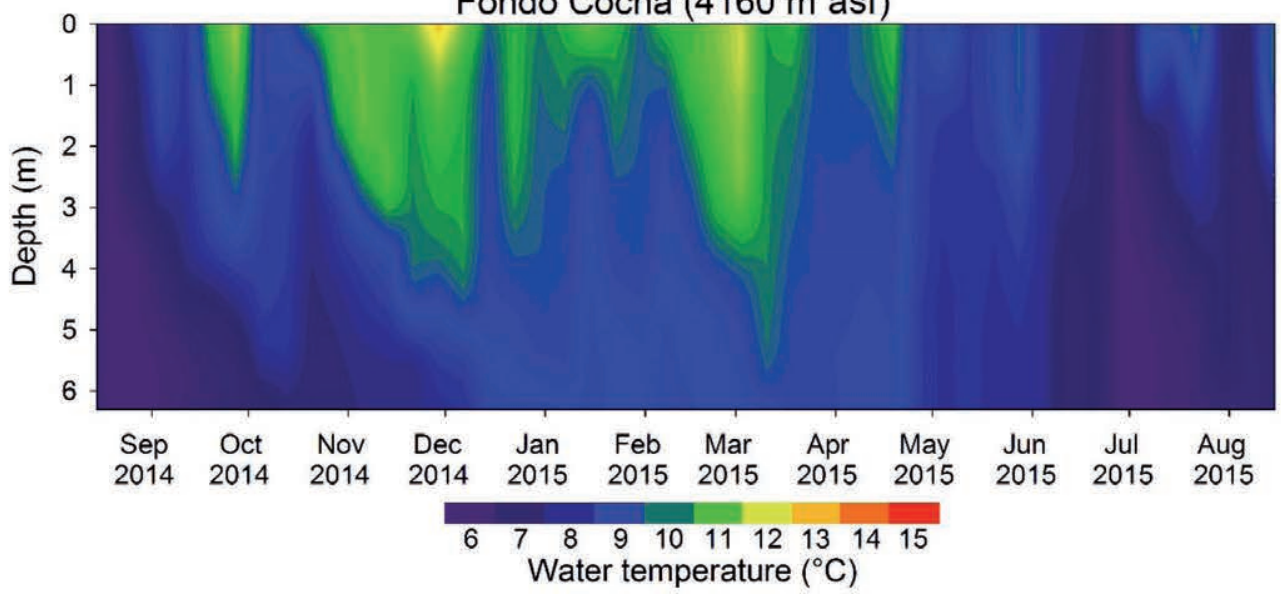

Fig. 2. Isothermal variations $\left({ }^{\circ} \mathrm{C}\right)$ versus time for all study lakes. 
tions, whereas the highest elevation, and shallowest lake (Fondo Cocha at $4160 \mathrm{~m}$ asl) recorded the coolest temperatures and the most frequent periods of isothermy (Fig. 2).

Despite differences in elevation gradients and basin morphometry, the study lakes show commonalities in their annual stratification and circulation patterns (Fig. 2), reflecting the influence of regional climatic variables, especially wind and temperature. Precipitation can also affect stratification, but a lack of high-quality stations with long-term data in these remote regions precludes assessment of its influence. The strongest and most continuous period of stratification occurred from early November to May, during which time mean monthly wind velocities were lowest and air temperatures were highest (Fig. 3). In contrast, the smallest temperature gradients and more isothermal periods occurred between May and October, when wind velocities were amongst their highest, and temperatures (particularly August - October, 2014) were low. Despite the variable climate that can occur in mountainous regions, the data from the nearby Cañar meteorological station ( $\sim 30 \mathrm{~km}$ away) appears to correlate well with many of the variations in thermal profiles, at least on a broad scale.

Extended periods of thermal stratification in lakes from the equatorial Andes have, thus far, been considered atypical. In rare instances, landscape features such as steep-sided basin morphometry and a sheltered landscape can result in perennial stratification (Bird et al., 2011); however, it is generally accepted that the thermal regime of equatorial mountain lakes, based on earlier limnological surveys, is cold polymictic with only infrequent periods of stratification (Hutchinson and Löffler, 1956; Steinitz-Kannan, 1997; Gunkel, 2000). In contrast, we show that extended periods of thermal stratification are now the norm in the study lakes, and the diatom-based paleolimnological studies (Michelutti et al., 2015a) suggest these lakes likely experienced a recent shift with respect to their stratification regimes. This shift is entirely consistent with changing climate conditions in this region over the last few decades. Local records of air temperature from the Cañar meteorological station show a warming trend since the 1970s, with a temperature increase of $1.15^{\circ} \mathrm{C}$ since that time. Concurrent with increasing temperatures, wind velocities have declined, with modern values often $40 \%$ lower compared to those of the 1960s and 1970s (Michelutti et al., 2015a).

A logical question is whether the thermal stratification of the study lakes represents an isolated event or a fundamental shift in physical properties driven by climatic changes of recent decades. Paleolimnological data from two of the study lakes (Toreadora and Llaviucu) provide temporal context for the temperature probe data. In fact, the sediment core studies predicted the density stratification patterns recorded here. High-resolution stratigraphic algal analyses from dated sediment cores revealed abrupt increases in the planktonic diatom Discostella stelligera

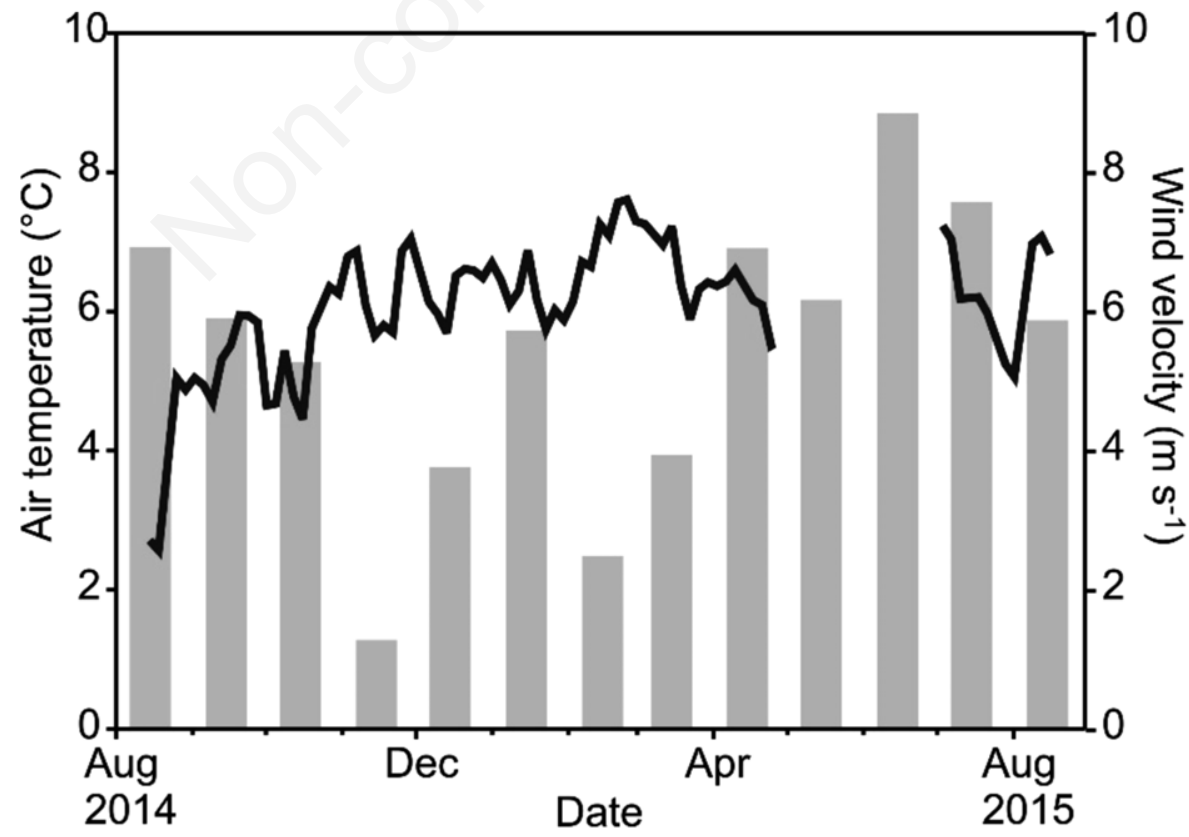

Fig. 3. Meteorological records of climatic drivers of thermal stratification including air temperatures plotted as a one week running mean (black line), and $500 \mathrm{hPa}$ mean monthly wind velocities (bars). No temperature data were recorded during June and July because of equipment failures. 
(basionym: Cyclotella stelligera) from trace abundances to dominance, concomitant with the increase in regional temperatures and declining wind speeds (Michelutti et al., 2015a). The rapid rise of D. stelligera was attributed to climate changes that enhanced the duration and strength of thermal stratification and allowed this taxon to proliferate at the expense of other taxa that required a more turbulent, well-mixed water column (Rühland et al., 2015). Greater periods of thermal stratification were also invoked to explain trends in whole lake production, as inferred from sedimentary chlorins, which decreased in the deepest study lake, Laguna Toreadora (Michelutti et al., 2015a). Declines in aquatic production can occur as a result of greater periods of stratification that curtail the upwelling of hypolimnetic nutrients into the surface waters (O'Reilly et al., 2003). Our temperature probe data (Fig. 2), together with the paleolimnological inferences, provide strong evidence that the study lakes have entered new physical states of enhanced water column stratification.

\section{CONCLUSIONS}

With the onset of intensified warming in this region, we suggest that the study lakes have crossed critical thermal thresholds, which ultimately can affect a wide spectrum of lake ecosystem properties. The earliest surveys from the 1980s reported that mountain lakes of Ecuador located above $3000 \mathrm{~m}$ asl rarely surpassed temperatures of $12^{\circ} \mathrm{C}$ (Steinitz-Kannan 1997), whereas our data show that it is not uncommon for surface temperatures to exceed $12^{\circ} \mathrm{C}$ (Fig. 2). However, these are still cold water lakes, and in comparison to warmer low elevation tropical lakes it is important to note that a similar degree difference between the epilimnion and hypolimnion does not result in equally stable stratification given the larger density difference per degree change at higher temperatures. Nonetheless, our data show that the study lakes experience extended periods of stable thermal stratification (Supplementary Fig. 5) and can no longer be considered cold polymictic, as originally described (Steinitz-Kannan et al., 1983).

At present, the classification of the study lakes based on circulation patterns would likely fall somewhere between oligomictic and warm monomictic, which is not unlike many tropical lakes at lower altitudes. Climate-induced changes to lake physical mixing processes have already caused ecosystem-scale changes to the study sites including the reorganization of phytoplankton communities and changes in nutrient cycling with attendant declines in whole lake production (Michelutti et al., 2015a). Similar changes appear underway for lakes elsewhere in the equatorial Andes (Michelutti et al., 2015b). Given projections of rising temperatures in the Andes (Diaz et al., 2014), equatorial mountain lakes will continue to experience dramatic changes that are likely to be exacerbated by increasing human pressure on water resources.

\section{ACKNOWLEDGMENTS}

This research was funded by a Natural Sciences and Engineering Research Council of Canada grant to JPS. Juan Carlos Quezada Ledesma, Pablo Vernardo Mosquera Vintimilla, and José Caceres at ETAPA-EP Parque Nacional El Cajas provided assistance for our field work and research permits. Matthias Vuille kindly provided wind data.

\section{REFERENCES}

Bird BW, Abbot MB, Vuille M, Rodbell DT, Stansell ND, Rosenmeier MF, 2011. A 2300-year-long annually resolved record of the South American summer monsoon from the Peruvian Andes. P. Natl. Acad. Sci. USA 108:8583-8588.

Diaz HF, Bradley RS, Ning L, 2014. Climatic changes in mountain regions of the American Codillera and the tropics: historical change and future outlook. Arct. Antarct. Alp. Res. 46:735-743.

Gerten D, Adrian R, 2002. Effects of climate warming, north atlantic oscillation, and El Niño-Southern oscillation on thermal conditions and plankton dynamics in northern hemispheric lakes. ScientificWorldJournal. 2:586-606.

Gunkel G, 2000. Limnology of an equatorial high mountain lake in Ecuador, Lago San Pablo. Limnologica 30:113-120.

Gunkel G, Casallas J, 2002. Limnology of an equatorial high mountain lake-Lago San Pablo, Ecuador: the significance of deep diurnal mixing for lake productivity. Limnologica 32:33-43.

Hampton SE, Gray DK, Izmest'eva LR, Moore MV, Ozersky $\mathrm{T}, 2014$. The rise and fall of plankton: Long-term changes in the vertical distribution of algae and grazers in Lake Baikal, Siberia. PLoS One 9:e88920.

Herzog SK, Martínez R, Jørgensen PM, Tiessen H [eds.] 2011. Climate change and biodiversity in the tropical Andes. Inter-American Institute for Global Change Research (IAI) and Scientific Committee on Problems of the Environment (SCOPE): $348 \mathrm{pp}$.

Hutchinson GE, Löffler H, 1956. The thermal classification of lakes. P. Natl. Acad. Sci. USA 41:84-86.

Kalnay E, Kanamitsu M, Kistler R, Collins W, Deaven D, Gandin L, Iredell M, Saha S, White G, Woollen J, Zhu Y, Leetmaa A, Reynolds R, Higgins W, Janowiak J, Mo KC, Ropelewski C, Wang J, 1996. The NCEP/NCAR 40-year reanalysis project. Bull. Amer. Meteor. Soc. 77:437-470.

Lewis WM, 1973. The thermal regime of Lake Lanao (Philippines) and its theoretical implications for tropical lakes. Limnol. Oceanogr. 18:200-217.

Löffler H, 1964. The limnology of tropical high-mountain lakes. Verh. Int. Ver. Limnol. 15:176-193.

Magrin G Gay García C, Cruz Choque D, Giménez JC, Moreno AR, Nagy GJ, Nobre C, Villamizar A, 2007. Impacts, adaptation and vulnerability, p. 581-615. In M.L. Parry, O. F. Canziani, J.P. Palutikof, P.J. van der Linden and C.E. Hanson (eds.), Contribution of Working Group II to the Fourth Assessment Report of the Intergovernmental Panel on Climate Change. Cambridge University Press, Cambridge.

Michelutti N, Wolfe AP, Cooke CA, Hobbs WO, Vuille M, Smol JP, 2015a. Climate change forces new ecological 
states in tropical Andean lakes. PLoS One 10:e0115338.

Michelutti N, Cooke CA, Hobbs WO, Smol JP, 2015b. Climatedriven changes in lakes from the Peruvian Andes. J. Paleolimnol. 54:153-160.

Michelutti N, Lemmen JL, Cooke CA, Hobbs WO, Wolfe AP, Kurek J, Smol JP, 2016. Assessing the effects of climate and volcanism on diatom and chironomid assemblages in an Andean lake near Quito, Ecuador. J. Limnol. 75:275286. Erratum in J. Limnol. 75:287.

O'Reilly CM, Alin SR, Pilsnier PD, Cohen AS, McKee BA, 2003. Climate change decreases aquatic ecosystem productivity of Lake Tanganyika, Africa. Nature 424:766-768.

Rühland KM, Paterson AM, Smol JP, 2015. Diatom assemblage responses to warming: reviewing the evidence. J. Paleolimnol. 54:1-35.
Steinitz- Kannan M, 1997. The lakes in Andean protected areas of Ecuador. The George Wright Forum 14:33-43.

Steinitz-Kannan M, Colinvaux PA, Kannan R, 1983. Limnological studies in Ecuador: 1. A survey of chemical and physical properties of Ecuadorian lakes. Arch. Hydrobiol. Suppl. 65:61-105.

Vuille M, 2013. Climate change and water resources in the tropical Andes. Inter-American Development Bank Technical Note No. 515.

Vuille M, Bradley RS, Keimig F, 2000. Climate variability in the Andes of Ecuador and its relation to tropical Pacific and Atlantic sea surface temperatures anomalies. J. Climate 13:2520-35.

Vuille M, Francou B, Wagnonc P, Juend I, Kaserd G, Marke BG, Bradley RS, 2008. Climate change and tropical Andean glaciers: past, present and future. Earth Sci. Rev. 89 79-96. 